\title{
Research on Novel Information Management Mode for Construction Engineering based on Big Data and Information Enhancement
}

\author{
Yan Wang ${ }^{1}$ \\ ${ }^{1}$ Xi'an Siyuan University, \\ Shaanxi, 710038 China
}

\begin{abstract}
In this paper, we conduct research on the novel information management mode for construction engineering based on big data and information enhancement. In recent years, China's economy shows the characteristics of diversification of market, the internationalization of economic activity in the driving the development of the society of city construction. Construction engineering project management reform and innovation, the first thing to do is enterprise senior leaders and managers to give enough attention and support which will be shown in detail in the paper.
\end{abstract}

Keywords: Information Management Mode; Construction Engineering; Big Data; Information.

\section{Introduction}

Economic growth has been a high-speed growth in our country, and from the point of national economy as a whole development, our country's industrial production, construction, retail sales, such as overall good fundamentals, which means that China's economy in the next few years to continue rapid growth potential is very strong. In recent years, China's economy shows the characteristics of diversification of market, the internationalization of economic activity in the driving the development of the society of city construction, under this background, the construction industry has been rapid development, the construction industry as the pillar industry of national economy, also faces a very broad prospects for development. The status of the construction project management is also growing. The management of construction enterprises in our country has accumulated rich experience, and has obtained the very good development. Construction project management still exist many problems, however, to a large extent hindered the enterprise's survival and development, therefore, construction enterprises only consciously specification quality problem, strengthening of quality control in the design, construction, to reduce and avoid the accident of the quality, enhance the corporate image. Construction projects in our country have not yet been perfect project management system, lack of professional project management team. At present our country has not specialized and systematic project management organization, only a small number of colleges and universities opened on this course. In addition, most of the construction units have never set up system of project management procedure and manual work, project management methods and means are backward, lack of advanced project management application software system.

Research and innovation process, innovation methods, it is necessary to set up an information perspective. Using the Angle of view, from the level of information to reveal the regularity of the activities in the innovation process and innovation by studying the information in the information space movement, the rule of transmission, transformation, proliferation, analyzing various innovations of existing methods, constructing innovation framework, for the study of creativity and innovation methods research is a new way. In the process of innovation, information from a known as the starting point of information movement, to extend the known information to other known 
information lap, intercourse proliferation of new information, and to form a new information channel, so as to make the original look blocked the road, the original looks do not make it, not exist. Information of course both appear to be coherent and also seem to be jumping or intermittent. Construction engineering project management reform and innovation, the first thing you need to enterprise senior leaders and managers to give enough attention and support, to further increase the funding related investment, change the previous traditional, conservative management thinking and management mode, establish the innovative consciousness, actively introducing and cultivating modern management talents, fully embodies the importance of project management innovation work urgency, create good working environment for all the management activities and security.

To combine the theory of data and information, in this paper, we research on the novel information management mode for construction engineering based on big data and information enhancement. Under the market economy, the implementation of the construction project, not only need a modern, professional construction technology and process, at the same time also need to take all kinds of modern management methods and means to improve the efficiency of project management quality. Establish perfect construction project management system is the foundation of the construction enterprise survival and development according to the size and complexity of the project is to establish a project management department, and reasonable configuration management personnel, to ensure the quantity and quality of the managers, to meet the needs of the project management. Through improving construction project management system, and implement the responsibilities for production, to ensure the management system to be effective, and promoting the advancement of management work. In the figure one, we show the sample of big data analysis and organization. In the following sections, we will discuss the issues in detail.

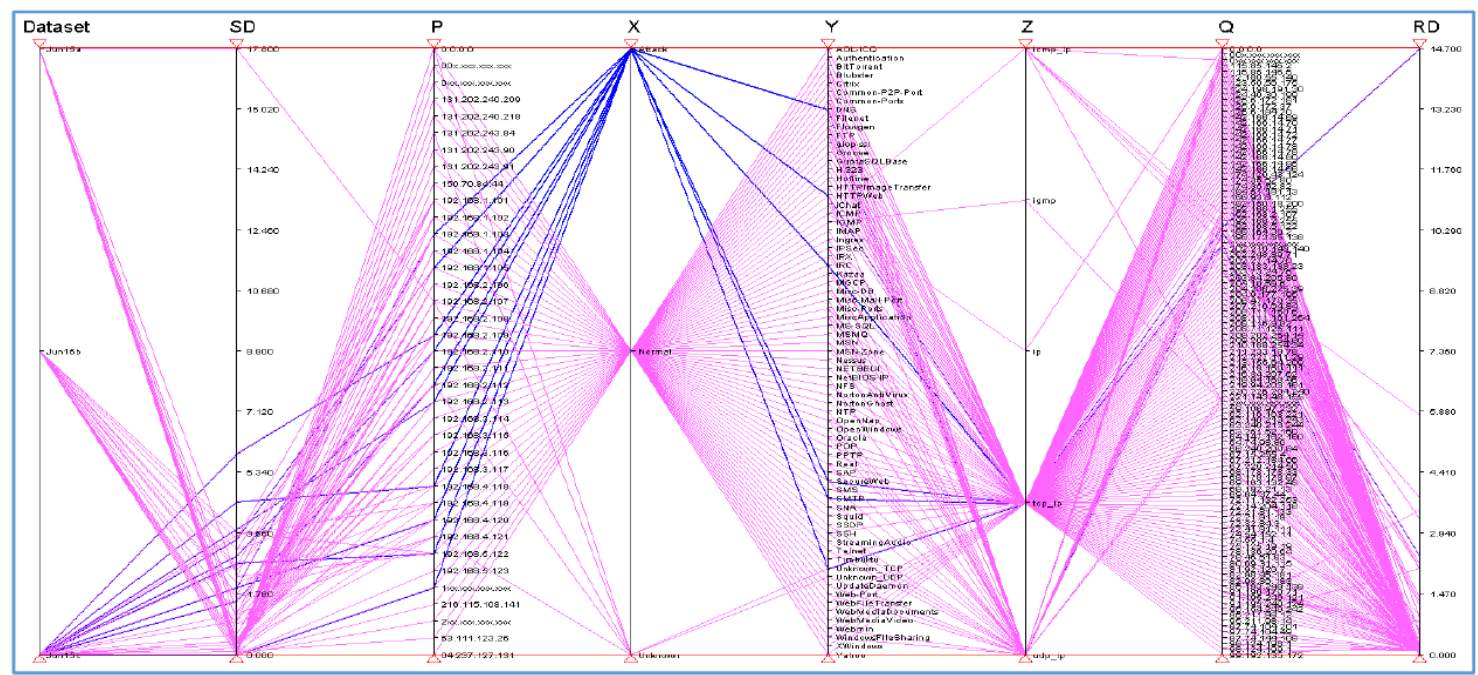

Fig. 1The Sample of Big Data Analysis and Organization for Construction Engineering

\section{The Principles of Our Method}

The Review of Construction Engineering. Construction enterprises want to get good development in the new situation which will need to establish a perfect system of project construction management and supervision mechanism to project management and supervision of general work thoroughly throughout the method in the process of the construction of the project and according to the 
actual situation of the enterprise itself to perfect management system and supervision mechanism of the yuan to improve the efficiency of management of construction projects and the importance of construction quality. Construction engineering project management innovation is in perfecting market economic system and the construction enterprises improve productivity level under the inevitable development trend, when carries on the management innovation, to pay attention to the innovation of according to certain principle, using advanced computer information technology, through establishing project management responsibility system and the related incentive constraints mechanism, to realize the sustainable development of construction engineering project management. Computer information technology is a great application value of advanced science and technology, make full use of information technology can greatly improve the level of productive forces which will promote the development of enterprises better.

The so-called project, usually is refers to the owner and the contract that construction enterprises between the scope of the project is known. Therefore, based on the market which must extend the construction project to the market, also is the construction project must be in the market, and in the markets for the implementation of construction projects, in the process of the implementation to further strengthen its competitiveness, again on this foundation to the participation of a new wave of market competition. Construction project management is a systematic and complex job, workload is very large, and because the importance of the construction projects, to demand is higher, the quality of management work just rely on human engineering with management is unsustainable, there are serious loopholes in management rules, and even endanger the safety of the construction project performance and operational performance. Followed by the scientific nature of the information technology, improve the quality of construction project management work, go deep into the each link of management, finds the problem in detail, the maximum to the protection of the quality of construction projects, using standard. Set up a technical analysis department, positive learning advanced construction technology and method in the developed countries, the introduction of foreign advanced construction technology, strengthening self-innovation ability which will better adapt to the requirements of today's modern society, but also provide technical support to ensure the quality.

The Information Enhancement and Big Data. The connotation of the information value is important. Information economics argues that the value of information is that it can satisfy people's some kind of utility, and reducing the sense of uncertainty. The definition of information has two level ontology and epistemology. Ontology hierarchy is the most common level, the highest when the constraint condition of the introduction of main body, is transformed into epistemology level. Ontology level of information is defined as the movement state of things and ways, epistemology is defined as the level of information expressed by the perceived or the subject motion state and its corresponding things change. Information publishers by means of information network and send the information to other users. At such a simple process of information value-added phenomenon, are the first to notice, in the process of information transmission and processing mainly refers to the syntactic information, semantic and pragmatic information cannot through information network transmission and processing, because they are grammatical information with a specific product of combination of object and subject, otherwise will lose its significance.

In the field of engineering and science and technology and the finite element analysis is a very effective numerical analysis method. Rough 
set theory is a kind of score incompleteness and uncertainty of mathematical tool, can effectively analyze and deal with imprecise, inconsistent, incomplete and so on all kinds of incomplete information. Produced from the given transaction database mining association rules is the process of association rule mining algorithm. Association rules algorithm is widely used the traditional algorithm is one of the classic algorithm for mining association rules. Encountered in the high-dimensional data, "curse of dimensionality" cannot correctly reflect the real similarity relation between objects, resulting in a wrong clustering results. At the same time, the size of the data, the dimensions of the data, data is sparse and noise will increase the difficulty of clustering. Clustering operation is essentially defines a equivalence relation between samples. Belong to the same class of any two sample points is considered to be equivalent, may think they have the similar properties, in the current threshold scales is no different. In accordance with the above features, the principle of the algorithm is that with each data as the center, to calculate the similarity between objects, and then based on similarity threshold partition initial equivalent relation of each object. In the figure two, we show the big data and information enhancement example.

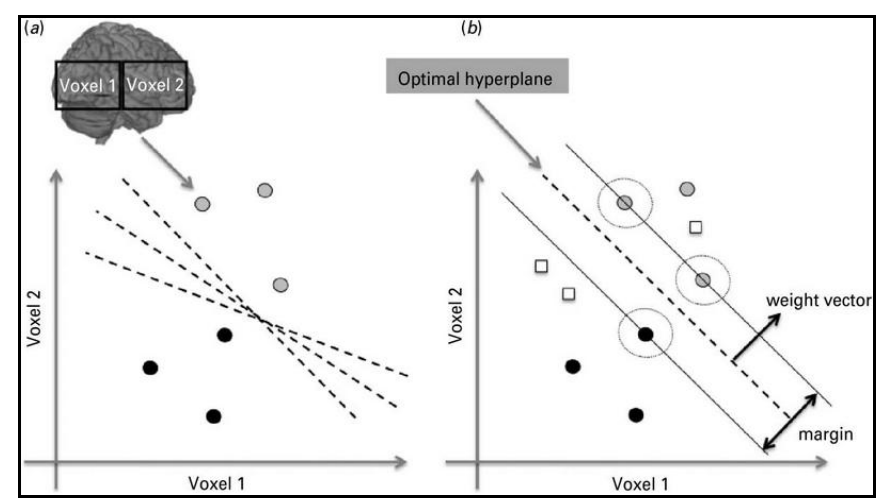

Fig. 2The Big Data Management and Information Enhancement Example

The Combined Methodology for Construction Engineering Management. With the opening up of construction market, a large number of migrant workers into the construction field, and gradually become the main body of construction engineering construction team. Because most of migrant workers through professional training, not to grasp the construction technology and construction standard, easy to cause the construction quality problems, influence the construction progress. With different positions, different requirements for personnel, pre-service training is very necessary. To minimize safety accidents, ensure project safety in production, you need to strengthen the construction safety management. In the construction engineering construction process, construction units need to put the security issue in the first place, implement the responsibility system for production, ensure that each have someone who's in charge of construction, timely find out the construction quality problems, eliminate safety hidden trouble. Construction engineering management information technology about many factors, so the information management of the implementation is difficult, for example the same construction enterprises with the same item of construction engineering, various departments, and even each staff demand differences, therefore the information technology of management platform does not apply to construction projects management. Based on this, we must build multi-level management platform, according to the different main body, and the corresponding data analysis and management, improve the quality of work, and realize the sharing of data, the specific requirements into every link for the management of construction projects which will improve the management level.

Is in the service of the construction project management and information technology, for the former, the latter is given priority to, so we must make clear the core position of construction engineering project management, everything from set out actually, do not follow, don't blindly follow, based on the actual situation of the 
enterprise itself, fully considering the objective characteristics and laws of construction engineering to help construction enterprises set up good social image and then improve the economic benefits of construction enterprises.

\section{Conclusion}

This paper discusses the research on the novel information management mode for construction engineering based on big data and information enhancement. Establish perfect construction project management system is the foundation of the construction enterprise survival and development according to the size and complexity of the project is to establish a project management department. In the construction engineering construction process, construction units need to put the security issue in the first place, implement the responsibility system for production. Our proposed methodology is novel and original which will help the companies to enhance the current management pattern.

\section{References}

[1] Abudayyeh O, Russell J, Johnston D, et al. Construction Engineering And Management Undergraduate Education[J]. American Society of Civil Engineers, 2014, 126(3):169-175.

[2] Tener R K. Industry-University Partnerships for Construction Engineering Education[J]. American Society of Civil Engineers, 2014, 122(4):156-162.

[3] Berg, R., \& Hinze, J. (2014). Theft and vandalism on construction sites. American Society of Civil Engineers, 131(7), 826-833.

[4] Riley D. An Interactive Visualization Environment for Construction Engineering Education[J]. American Society of Civil Engineers, 2014.

[5] Bj02rnsson H C, Ekstr02m M A. Valuing Flexibility in Architecture, Engineering, and Construction Information Technology Investments[J]. Journal of Construction Engineering \& Management, 2014, 131(4):págs.

431-438. 